\title{
Description and Categorization of Balti Tense Markers
}

\author{
* Iftikhar Hussain \\ ** Arshad Khan (Corresponding Author) \\ *** Amina Khalid
}

\begin{abstract}
The current study aims at describing and categorizing the possible tense markers of Balti language, spoken in the Baltistan region of Gilgit-Baltistan. As for linguistics exposure is concerned, Balti is one of the less explored languages. Balti has a handful amount of traditional pieces of literature in the form of books (Traditional Grammars, stories, and history) and even the available Balti literature have not been documented within the proper paradigm of linguistics. To conduct this particular study, 200 Balti root words (verbs) have been collected from the corpus data using both the naturalistic and documented sources. The selected 200 Balti root words (verbs) were critically described, analyzed, and categorized within the paradigm of inflectional morphemes of tense markers using the qualitative research design. The result shows that there are 11 tense markers, i.e., "-ed", "-en", "-set", "-s", "$u k "$, "-nuk", "-tuk", "-ik", "-in", "-se" and "-e" in Balti language. These tense markers are added to the respective root verbs to mark present indefinite, present participle, past participle, future indefinite, and future perfect tenses. This study will hopefully encourage future researchers to conduct research works on the various aspects of Balti language.
\end{abstract}

Keywords: Tense Markers, Morphology, Morpheme, Inflectional, Root Verbs

\section{Background of the Study}

Balti is a Tibeto-Burman language that belongs to the Western Tibetan sub-family. It is spoken primarily in the Gilgit-Baltistan region of northern Pakistan, known as Baltiyul (Balti State) and in neighboring region Ladakh in India (Pandey, 2011). Balti language is a family member of TibetoBurman of Sino-Tibetan family which is spoken in 4 districts (Skardu, Khaplu, Charming, and Tiger) of Baltistan region within Gilgit Baltistan by 4,00,000 speakers (Abbas, 2016).

The current study is connected to tense markers and it tries to explore an inconsequential dimension of Balti morphology "Tense markers". As for as the number of tense markers are concerned, the world languages show variation. Yule (2010) explains examples from world's languages, e.g. Aztec (a language from Central America); mic (die) + tia (cause to) $+\mathrm{s}$ (future) $=$ militias (will kill). Like that, another language 'spoken in the Philippines marks tense as e.g. basa (read), bumasa (read), and babasa (will read). In the above examples the infix '-um-' is placed at onset position for the past and the first syllable is repeated for the future. However, the Spanish language takes the suffix '- $r-e$ ' at the stem to convert presents tense into future tense, e.g. 'cant-o' (I sing) and 'canta-r-é' (I will sing). But Talgalog language has different tense marking system e.g., 'ibigay' (give)' 'ibinigay' ('gave), 'ipaglaba' (wash for), 'ipinaglaba' (washed for)' and 'ipambili' (buy with), 'ipinambili' (bought with). In these examples the infix '-in-'is followed by the first syllable (Haspelmath \& Sims, 2010). Likewise, the vowel /o/ is replaced by /e/in Coptic language e.g. ' $k o^{-} t$ ' (build) into ' $k e^{-} t$ ' (be built), ' $h o^{-} p$ ' (hide)' into ' $h e^{-} p$ '('be hidden) and 'to' $m$ ' (shut) into 'te' $m$ '(be shut) (Layton, 2000). But in Germanic language the prefix 'ge-' indicates past tense, e.g. 'finden' (find), 'ge-funded' (found), 'singen' (sing) 'ge-sungen' (sung) and 'binden' (tie) into 'gebunden' (tied).

Hindi language takes quite different inflectional morphemes with roots (verbs). For instance, ' $k h \bar{a}-t \bar{a}$ ' (eat), ' $k h \bar{a}-y \bar{a}$ ' (ate), ' $k h \bar{a} r \partial h-\bar{a}$ ' (is/was eating) and ' $k h \bar{a} e-g-\bar{a}$ ' (will eat). Both the habitual and perfective aspects are shown on the verb using suffixes, for instance '-ta' and ' $-y a$ ', and the auxiliary '-rzh' symbolizes progressive aspect and future tense is marked on the root as shown above

* Karakoram International University, Ghizer Campus Email: Iftikhar.eng@kiu.edu.pk

** University of Management and Technology, Lahore Email: arshad.khan@umt.edu.pk

*** University of Management and Technology, Lahore Email: amina.khalid@umt.edu.pk 
(Singh \& Sarma, 2011). Conventionally three tenses past, present, and future can be seen in both Urdu and Hindi. But only the first two tenses present and past are truly functional. The future is a complex mood category rather than tense. The present and past tenses are represented by stem 'tha' (past) and 'he' (present). The present auxiliary stem ' $h$ ' is followed by suffix '-o' and it is further followed by the string of morphemes ' $-g$ ', ' $-a$ '. This is purely presumptive mood rather than tense. For example, past; 'larka ne paisa beja-t-a th-a' (the boy sent money), present; 'larka paise bhej-t-a h-ai' (the boy sends money) and, in Future; 'larka jabtak paise bheje chukka h-o-g-a' (the boy will have sent the money by then), (Asif Aga, 1998). Ahmad R. Lotfi (2006) explains Persian tense marking as the suffix depends upon the subject, e.g. first person singular, 'raft-am' (I went), second-person singular 'raft-i' (you went) and third-person singular 'raft' (he/she went). Similarly, for first-person plural, 'raft-in' (we went), second-person plural 'raft-id/raft-in' (you went) and third-person plural 'raft-an' (they went). All, these are derived from the root "raftan" (to go). In Arabic imperfective verb is inflected for mode not perfective e.g. 'kataba' (he wrote) takes inflections; 'kataba' (he wrote), 'Lan yaktuba' (he won't write), 'Lam yaktub' (he didn't write) and imperfective is inflected as; 'yaktubu' (he writes) and 'sa-yaktubu' (he will write/will write), (Ali, 2013).

\section{Research Questions}

1. How many tense markers are there in the Balti language?

2. How can we categorize the Balti tense markers in different categories?

\section{Research Objectives}

The study aims:

1. To describe all the possible tense markers of the Balti language.

2. To categorize the possible tense markers of the Balti language in different categories.

3. To find out the total number of tense markers in the Balti language.

\section{Significant of the Study}

Balti is a language spoken by around 5 lac Balti speakers in the Baltistan region of northern Pakistan. Due to a lack of linguistic researchers in the region, not much research work has been done on this language so far. Apart from that, Balti is one of the most endangered languages in Pakistan due to the influence of Urdu and English languages. In this connection, the researchers of the region will have to conduct different research work for the preservation and revitalization of this language. Owning that, the researcher conducted this particular study which will be a great contribution for the Balti speakers to promote and preserve their language.

\section{Method}

A descriptive and qualitative research design has been employed for the present study. The study lacks a proper theoretical framework as it demands a description of possible tense makers of the Balti language. For this purpose, the collected data have been transcribed and critically analyzed. Data have been collected from two sources: naturalistic and documented. One set of lexical items have been taken from naturalistic conversations (naturalistic source) involving different Balti native speakers. For this purpose, data collection tools of observation and recording have been employed. First of all, natural conversation among Balti native speakers have been recorded. To do that 30 participants (Balti native speakers) have been selected. They have been divided into different groups and a day to day conversation was recorded. From the recorded conversations, the researcher observed and took 100 Balti root words (verbs). The second data set consisted of 100 Balti root words (verbs) which have been extracted from the three authentic books (documented sources) written by native Balti speakers. The documented source (books) consisted of 'Short Sketch of Balti Grammar by Hassan Lobsang' (1995), 'Balti Bol Chal by Fida Gasangi, (2011) and 'The Balti History by Hussain Abadi', (1985). The selected 200 Balti root words (verbs) were critically described, analyzed, and categorized within the paradigm of inflectional morphemes of tense markers descriptively using the qualitative research design.

\section{Analysis}

\section{Tense Markers in Balti}

\section{Present Tense (Indefinite)}

The inflection "-ed" marks present tense (present indefinite), when it gets attached with roots (verb), ending with both vowels and consonants. For instance, 'zer'(tell) ends with the consonant /r/, changes into present indefinite tense as "zer-ed" (tell/tells), "min" (give) ends with the consonant /n/, changes into its present tense as 'min-ed'(give/gives), and 'fchol'(request/pray) ends with the 
consonant $/ 1 /$, changes into "fchol-ed" (request/requests). Similarly, root words ending with vowels, e.g. "ngu" (weep) ends with the short vowel /u/, changes into present tense as "ngu-ed" (weep/weeps), "be" (do) ends with the diphthong /ei/, changes into "be-ed"(do/does) and the verb " rbi"(write) ends with the short vowel /i/, changes into "rbi-ed"(write/writes).

\section{Present Participle (Progressive)}

The inflection "-en" when gets attached with root verbs ending with either vowel or consonant marks present participle tense. For instance, the root verbs 'zer'(tell), "min" (give) and ' $\mathrm{fchol}$ '(request) end with consonants $/ \mathrm{r} /, / \mathrm{n} /$ and $/ 1 /$ respectively change into participle by adding "en". And root verbs "nu" (weep), "bei" (doing) and "rbi" (write) end with vowels /u/, /ei/ and /i/ also become participle when /en/ attaches with these verbs. Like English, Balti present participle verbs take various auxiliaries as: for present tense "yod", for past "yod-pa" and future "duktuk" are used with the present participle form of verb.

\section{3. $\quad$ Past Participle (Perfect Tense)}

The inflection "-set" marks participle (past participle/perfect tense), when it gets attached with roots (verb) ending with both vowels and consonant sounds. Such as, roots(verb) ending with consonants, e.g. 'zer'(tell) ends with the consonant /r/, changes into past participle/perfect, as "zerset" (told), "gon"(wear) ends with the consonant /n/, changes into past participle/ perfect tense 'gonset'(worn), and 'fchol'(request) ends with the consonant $/ 1 /$, changes into past participle/perfect "fchol-set" (requested). In the same way, root words ending with vowels, e.g. "zogo" (bend) ends with the short vowel $/ \mathrm{u} /$, changes into a past participle, e.g. "zogo-set" (bent), the verb "bei" ends with the diphthong /ei/, changes into past participle "bei-set" (done) and the verb "rbi" (write) ends with the short vowel /i/, changes into past participle as "rbi-set" (written).

\section{4. $\quad$ Past Tense (Indefinite)}

The inflection "-s" marks past indefinite tense when it gets attached with roots (verb) ending with both vowels and consonants. For instance, Balti root words ending with consonants e.g. 'zer'(tell) ends with the consonant/r/ changes into past tense as "zer-s" (told), "min" (give) ends with the consonant $/ \mathrm{n} /$, changes into past tense as 'min-s'(gave), and 'fchol'(request/pray) ends with the consonant $/ 1 /$, changes into past tense as "fchol-s" (requested/prayed). Likewise, root words (verb) ending with vowels in Balti, e.g. "nu" (weep) ends with the short vowel /u/ changes into past tense as "nu-s" (wept), "bei"(do) ends with the diphthong /ei/ changes into "be-s"(did) and the verb " rbi"(write) ends with the short vowel /i/ changes into past tense as rbi-s(wrote). But the root words (verb) "ze" (eat) has an exception in this regard that it changes into "zo-s" (ate), the root word "ze" losses its last sound, "ei" and it is replaced by / $/ 2 /$, and then the inflection "-s" is added at the end.

\section{Future Tense (Consonant Ending)}

The inflection " $u k$ " marks future indefinite tense when it gets attached with roots (verb). In addition, it has been found that roots (verbs) ending with few particular consonants $(/ \mathrm{t} /, / \mathrm{l} /, / \mathrm{n} /, / \mathrm{r} /$ and $/ \mathrm{s} /$ ) only take the inflection "-uk" as a future tense marker in Balti Language. Such as, the verb 'zer'(tell) ends with the consonant / $\mathrm{r}$ / changes into future tense "zer-uk" (will tell), "min" (give) ends with consonant $/ \mathrm{n} /$ changes into future tense 'min-uk' (will give) 'fchol' (request) ends with the consonant /l/ changes into future indefinite tense "fchol-uk", (will request). Chat (cut) ends with the consonant /t/ changes into future tense "chat-uk" (will cut) and the verb "shes" (know) ends with the consonant /s/ sound changes into future tense "shes-uk" (will know).

While root words (verb) ending with the consonant $/ \mathrm{m} /$ and $/ \mathrm{y} /$ take the inflection "-nuk" as a future tense marker in Balti Language. As, the verb 'tham'(fight) ends with the consonant $/ \mathrm{m} / \mathrm{changes}$ into future indefinite tense "tham-nuk" (will fight), "skam" (dry) ends with consonant $/ \mathrm{m} / \mathrm{changes}$ into future tense "skam-nuk" (will dry) "phhang" (throw) ends with the consonant $/ \mathrm{y} /$ changes into future indefinite tense "phhang-nuk" (will throw) and "thhung" (drink) ends with the consonant $/ \mathrm{y} /$ changes into future tense "thhung-nuk" (will drink).

Whereas, the inflection morpheme "-tuk" also marks future indefinite tense, when it gets attached with roots (verbs) ending with few particular consonants $(/ \mathrm{p} / / / \mathrm{b} /$ and $/ \mathrm{k} /$ and $/ \mathrm{g} /$ ). For example, the verb 'thhop'(find) ends with the consonant $/ \mathrm{p} /$ changes into future tense "thhop-tuk" (will fine), "duk" (sit) ends with consonant $/ \mathrm{k} /$ changes into future tense "duk-tuk" (will sit) "nuub" (drown/set) ends with the consonant /b/ changes into future tense "nuub-tuk" (will drown) and "jig" (fear) ends with the consonant /g/ changes into future tense "jig-tuk" (will fear). 


\section{6. $\quad$ Future Indefinite (Vowel Ending)}

The inflectional morpheme " $i k$ " marks future indefinite when it gets attached with roots (verbs) ending with vowel sounds. For instance, the verb 'bei'(do) ends with the diphthong /ei/ changes into future indefinite tense "bei-ik" (will do), "nu" (weep) ends with the vowel /u/ changes into its future tense "nu-ik"(will weep) and the root verb "shi"(die) ends with the short vowel /i/ changes into future indefinite tense "shi-ik" (will die).

Similarly, the inflection "-in" also marks future Indefinite tense when it gets attached with roots (verbs) ending with vowel sounds. As the verb 'bei'(do) ends with the diphthong /ei/ changes into future indefinite tense as "be-in" (will do), "nu" (weep) ends with the vowel /u/ changes into future tense "nu-in" (will weep) and the root verb "shi" (die) ends with the short vowel /i/ changes into future indefinite tense "shi-in", (will die). The above analysis reveals, both "-in" and " $i k$ " mark future indefinite tense) when attach with the Balti vowel ending roots (verbs).

\section{7. $\quad$ Future Perfect Tense}

The inflections "-se" and "-e" mark future perfect tense by attaching to roots (verb) ending with both consonant and vowel sounds. Both "-se" and " $-e$ " mark conjunctive past participle (past participle) on Balti roots. Root words (verbs) ending with consonants 'thhop'(fine) ends with the consonant /p/ changes into future tense (future perfect) "thhop-se duktuk" (will have found), "khirl" (fight) ends with consonant / $1 /$ changes into future tense (Perfect) "khirl-e duktuk" (will have fought) "bud" (fall) ends with the consonant /d/ changes into future tense (perfect) "bud-e duktuk" (will have fallen), and "zer" (tell) ends with the consonant / $\mathrm{r} /$ changes into future tense as "zer-e duktuk" (will have told).

On the other hand, the Balti roots (verbs) ending with vowels take only the inflection "-se", e.g. "rbi" ends with the short vowel /i/ changes into future perfect "rbi-se duktuk" (will have written), "ze" (eat) ends with the diphthong /ei/ changes into future tense perfect "zo-se duktuk" (will have eaten) and the verb "nu" (weep) ends with the short vowel /u/ changes into future tense perfect "nu-se duktuk" (will have wept).

\section{Discussion and Findings}

As much as linguistics exposure is concerned languages vary with respect to the degree of experience. Balti is one of the languages, which has the least amount of exposure in this regard. There is a handful amount of literature in the form of books (Traditional Grammars, stories, and history) in the Balti language but the most important linguistic aspect 'morphology' has been untouched yet linguistically. Even the available Balti literature has not been documented within the proper paradigm of linguistics.

So for from the available literatures; Short Sketch of Balti Grammar, a traditional grammar, composed by Lobsang (1995) describes Balti words formations process as: Numbers in noun and verb in tenses; for example, 'fro' (boy) can be pluralized by adding inflection "-ng" as 'fro-ng' (Boys), by the same token 'Barban' (window) can be pluralized by adding the inflection "-kun" that will be 'barban-kun' (windows). What's more, in the context of verb changes can be applied such as the word 'zaed' (eat) is its present form that can be converted into past by using the word 'pa' so the word in past form is attributed as 'zosed-pa' (ate) and in future 'ze-in' (will eat) as well as 'za'(eat) into 'zakhan'(eater) and 'zakhan-kon'(eaters).

It seems that the Balti language also indicates a complex tense marking system. Balti verb is inflected in many ways such as; e.g. 'rabya'(write), 'rabis'(wrote), 'chaqpa'(break), 'chaqes'(broke) and 'tyangma'(beat), 'tyanges'(beat) and further, the inflection '-ed' and '-pa' make present perfect and past perfect respectively, e.g. 'mo zan zos-ed' (she has taken food), 'kho khatchi rabi-sed' (he has written a letter), 'kho khatchi rabi-sed-pa' (he had written a letter) 'mo zan zose-d-pa' (she had taken food). Similarly, verbs also take inflection '-ed' or 'yod' in present tense and remove 'alef', 'ma', 'ya', 'ba', 'pa' 'wa' and 'fa' from the ending of verbal noun, e.g. 'kho helt-ed' (he looks), and 'kho helten yot' (he is looking) (Ghansangi, 2011).

However, the current study described and categorized the possible tense markers of the Balti language. The study found the following findings: There are11 tense markers, i.e., "-ed", "-en", "-set", "-s", "-uk", "-nuk", "-tuk", "-ik", "-in", "-se" and "-e" have been found in Balti Language. These tense markers are added to the respective roots (verbs) to mark present indefinite tense, present participle (continuous tense), past participle (perfect tense), Future Indefinite tense, and Future Perfect in Balti. The findings can be further illustrated through the following discussion. 


\section{Present Tense (Indefinite)}

The analysis shows that in Balti Language the tense marker "-ed" marks present tense (present indefinite) when it gets attached with roots (verbs). The analyzed descriptions of the tense marker (ed) can be further illustrated through the examples as:

1. $\mathrm{Kho}(\mathrm{He})$ zan(food) za-ed(eats).

He eats food.

In the above Balti sentence, the root verb za(eat) ends with the short vowel takes the marker (-ed) as the present indefinite tense marker.

2. $\mathrm{Na}(\mathrm{I})$ polo (the ball) phang-ed(throw).

I throw the ball.

In the above sentence, the root verb phang(throw) ends with the consonant $/ \mathrm{y} /$ again takes the same tense marker (-ed) as the present indefinite marker

\section{Present Participle (Continuous Tense)}

The analysis shows that the Balti inflectional morpheme "-en" marks present participle (continuous tense) when it gets attached with roots (verbs). Like English, Balti present participle also takes various auxiliaries as in present tense (present continuous) it is accompanied with the auxiliary "yod", in past tense (past continuous) the participle takes the auxiliary "yod-pa" and in future continuous the auxiliary "duktuk" is added with the participle. The analyzed descriptions of the tense marker(-en) can be further explained through the following Balti sentences:

1. $\mathrm{Kho}(\mathrm{He})$ zan(food) za-en(eating) yod(auxiliary).

He is eating food.

In the above Balti sentence, the root verb za(eat) ends with the short vowel takes the marker (-en) progressive tense marker. Here 'yod' is functioning as an auxiliary (is, am, and are) accompanied with the main verb to show present progressive tense.

2. $\quad \mathrm{Kho}(\mathrm{He}) \mathrm{zan}$ (food) za-en(eating) yod-pa (auxiliary).

He was eating food.

In the above Balti sentence, the root verb za(eat) ends with the short vowel takes the marker (-en) progressive tense marker. However, 'yod-pa' is functioning as an auxiliary (was/were) accompanied with the main verb to show past progressive tense.

3. $\mathrm{Kho}(\mathrm{He})$ zan(food) za-en(eating) duktuk(auxiliary).

He will be eating food.

In the above Balti sentence, the root verb za(eat) ends with the short vowel takes the same marker (-en) as a progressive marker. Here 'duktuk' is functioning as an auxiliary (will be) accompanied by the main verb to show future progressive tense.

4. $\mathrm{Na}(\mathrm{I})$ polo (the ball) phang-en(throw) yod (auxiliary).

I am throwing the ball.

In the above sentence, the root verb phang(throw) ends with the consonant $/ \mathrm{y}$ / again takes the same tense marker (-en) as a progressive marker. But, 'yod-pa' is again functioning as an auxiliary(was/were) accompanied with the main verb to show past progressive marker.

5. Khong (They) polo (the ball) phang-en (throw) yod-pa (auxiliary).

I was throwing the ball.

In the above sentence, the root verb phang (throw) ends with the consonant $/ \mathrm{y} /$ again takes the same tense marker (-en) as a progressive marker. But, 'yod-pa' is functioning as an auxiliary (was/were) accompanied with the main verb to show past progressive tense.

6. $\mathrm{Na}(\mathrm{I})$ polo (the ball) phang-en (throw) duktuk (auxiliary).

I will be throwing the ball.

In the above sentence, the root verb phang (throw) ends with the consonant $/ \mathrm{y} /$ again takes the same tense marker (-en) as a progressive marker. But, 'dutuk' is functioning as an auxiliary (will be) accompanied with the main verb to show future progressive tense

\section{Past Participle (Perfect Tense)}

The analysis shows that "-set" marks past participle (present perfect tense and past perfect) when it is attached with roots (verbs). Unlike English, Balti past participle don't take an auxiliary in present perfect tense yet in past tense (perfect) the participle takes the auxiliary "pa". The analyzed descriptions of the tense marker (-set) can be further explained through the following Balti sentences: 
1. Kho (He) zan (food) zo-set (has eaten).

He has eaten food.

In the above Balti sentence, the root verb zo (eat) ends with the short vowel takes the marker (-set) to marks past participle.

2. $\quad$ Kho (He) zan (food) zo-set-pa (had eaten).

He had eaten food.

In the above Balti sentence, the root verb zo (eat) ends with the short vowel takes the marker (-set) to mark past participle. However, '-pa' is functioning as an auxiliary (had) accompanied with the main verb to show past perfect tense.

3. $\mathrm{Na}(\mathrm{I})$ polo (the ball) phang-set (have thrown).

I have thrown the ball.

In the above sentence, the root verb phang(throw) ends with the consonant $/ \mathrm{y} /$ again takes the same tense marker (-set) as the past participle marker.

4. Khong (They) polo (the ball) phang-set (had thrown) pa (had).

I had thrown the ball.

In the above sentence, the root verb phang (throw) ends with the consonant $/ \mathrm{y} /$ again takes the same tense marker (-set) as the past participle marker. But, '-pa' is functioning as an auxiliary (had) accompanied with the main verb to show past perfect tense.

\section{Past Tense (Indefinite)}

The analyzed data shows that "-s" marks past tense (indefinite/simple) when it gets attached with roots (verbs). The analyzed descriptions of the tense marker (-s) can be further exemplified through the following Balti sentences:

1. $\quad \mathrm{Mo}(\mathrm{He})$ choh (water) thong-s (drank).

He drank water.

In the above Balti sentence, the root verb thong (drink) ends with the consonant $/ \mathrm{y} /$ takes (-s) to mark past indefinite tense.

2. Na-si (I) polo (the ball) len-s (bought).

I bought the ball.

In the above sentence, the root verb len (throw) ends with the consonant $/ \mathrm{n} /$ again takes the same tense marker (-s) to show past indefinite tense.

3. Khong (They) sabaq-po (the lesson) rebi-s (wrote).

They wrote the lesson.

In the above sentence, the root verb rebi (write) ends with the short /i/ again takes the same tense marker (-s) as the past indefinite marker.

Future Tense (Indefinite)

The above analysis shows that the tense markers, i.e., "-uk", “-nuk", "-tuk", "ik" and "in" mark future tense (indefinite/simple) when they are attached to roots (verbs).

- $\quad$ From the above tense markers "-uk" marks future tense (Future Indefinite Tense) when the roots are ending with the consonants $(/ \mathrm{t} /, / \mathrm{l} /, / \mathrm{n} /, / \mathrm{r} /$ and $/ \mathrm{s} /)$. The analyzed descriptions of the tense marker(-uk) can be further illustrated through the following Balti sentences:

1. Kho (He) shoqbo (book) zer-uk (will read).

He will read a book.

In the above Balti sentence, the root verb zer (read) ends with a consonant (r) takes the marker (-uk) as a future tense marker.

2. Mo (Shee) imtihan-chi (exame) min-uk (will give/appear).

He will give/appear in the exam.

In the above Balti sentence, the root verb min (give) ends with the consonant (n) again takes the same tense marker (-uk) as a future marker.

3. Kho $(\mathrm{He})$ nala (me) fochul-uk (will request).

He will request me.

In the above Balti sentence, the root verb fochul (request) ends with consonant / $1 /$ takes the same marker (-uk) to mark future tense.

4. Khong (They) staghjee (tree) chat-uk (will cut).

They will cut the tree. 
In the above sentence, the root verb chat(cut) ends with the consonant/t / again takes the same tense marker (-uk) as the future tense marker.

5. Amjad laspo (the task) bes-uk (will do).

Amjad will do the work/task.

Following the above pattern, in the above-mentioned Balti sentence, the root verb bes (do) ends with consonant /s/ takes the same marker (-uk) to mark future tense.

- The inflection "-nuk" is another future tense marker that is added when the roots (verbs) are ending with the consonants $(/ \mathrm{m} /$ and,$/ \mathfrak{n} /)$. The analyzed descriptions of the tense marker (-nuk) can be further illustrated through the following Balti sentences:

1. Kho (He) dushmana (enemy) tham-nuk (will fight).

He will fight with the enemy.

In the above Balti sentence the root verb that (fight) ends with a consonant (m) takes the marker (-nuk) as a future tense marker.

2. Ashraf polo (the ball) phang-nuk (will throw).

Ashraf will throw the ball.

In the above sentence the root verb phang (throw) ends with the consonant $/ / \mathrm{y} /$ again takes the same tense marker (-nuk) as the future tense marker.

- The inflection "-tuk" again marks future tense (future indefinite tense) when it is attached to roots ending with the consonants $(/ \mathrm{p} /$, and $/ \mathrm{b} /, / \mathrm{k} /$ and $/ \mathrm{g} /)$. The analyzed descriptions of the tense marker(-tuk) can be further exemplified through the following Balti sentences:

1. Nala (I) laskha (job) thhop-tuk (will get).

I will get a job.

In the above Balti sentence the root verb thhop (get) ends with a consonant (p) takes the marker (-tuk) as a future tense marker.

2. Mo (Shee) nano (home) duk-tuk(will be).

He will be at home.

In the above Balti sentence the root verb duk (be) ends with the consonant (k) again takes the same tense marker (-tuk) as a future marker.

3. Nimo (The sun) nuub-tuk (will set)

The sun will set.

In the above Balti sentence the root verb nuub(set) ends with consonant /b/ again takes the same marker (-tuk) as a future tense marker.

4. Khong (They) Jig-tuk (will get fear).

They will get fear.

In the above sentence the root verb jig (get fear) ends with the consonant/g/ again takes the same tense marker (-tuk) as the future tense marker.

- The tense markers both "-ik" and "-in" are used as substitutes for each other when the roots are ending with vowels. The analyzed descriptions of the tense marker(-ik) can be further demonstrated through the following Balti sentences:

1. Kho (he) las-po (the task) bei-ik (will do).

He will do the task.

In the above Balti sentence the root verb bei (do) ends with the diphthong /ei/ takes the marker (-ik) as a future tense marker.

2. $\quad$ Mo (She) nu-ik (will weep).

She will weep.

In the above Balti sentence the root verb nu (weep) ends with the short vowel (u) again takes the same tense marker (-tuk) as a future marker.

\section{Future tense (Perfect)}

The analysis shows that in Balti Language the tense markers, i.e., "-se", and "-e", mark future (Future Perfect Tense) when they are attached with root words (verbs) ending with both consonants and vowels. Both "-se" and "- $e$ " mark conjunctive past participle (past participle) on Balti roots (verbs). The analyzed descriptions of the tense marker "-se" and "-e" can be further demonstrated through the following Balti sentences: 
1. Kho (he) las-po (the task) bei-e duktuk (will have done).

He will have done the task.

In the above Balti sentence the root verb bei (do) ends with the diphthong /ei/ takes the marker (-se) as a future perfect marker. The analyzed descriptions of the tense marker (-e) can be further demonstrated through the following Balti sentences:

2. Mo (She) polo (ball) phang-se-duktuk (will have thrown).

She will have thrown the ball.

In the above Balti sentence the root verb phang (throw) ends with the consonant $/ \mathrm{y} /$ takes Conclusion

tense marker (-se) as a future perfect tense marker).

The study concludes that the Balti language is a less explored language having no proper linguistic breakthrough in the field of morphology. The current study tried to expose an inconsequential dimension of Balti morphology "Tense markers". The collected data have been analyzed descriptively keeping in view the features of inflectional morpheme; chiefly features of tense markers. The study found 11 tense markers marking various tenses such as present indefinite tense, present participle (continuous tense), past participle (perfect tense), future indefinite tense, and future perfect. From the Balti tense marker '-ed' marks present tense, '-en' marks present participle, '-set' marks past participle, '-s' marks past tense, 'uk', '-nuk', '-tuk', '-ik' and '-in' mark future tense and finally '-e' and '-se' mark future perfect tense; conjunctive past participle (past participle). The current study is an attempt to open doors for the future researchers and encourage them to study other aspects of Balti morphology particularly its case and aspects markers.

\section{References}

Abbas, G. (2016). Description and Classification of Balti Consonants. Lahore: Pakistan: Unpublished Thesis University of Management and Technology.

Ahmad R. Lotfi (2006). Agreement in Persian. Esfahan: Linguistic Online.

Aga, A. (1998). Form and Function in Urdu-Hindi Verb Inflection. New York: Sage Publication.

Ali, A. S. (2013). The Verbal System of Malay and Arabic: Contrastive Analysis. International Journal of Business and Social Science Vol. 4 No. 1

Driem, V. (2004). Languages of the Himalayas Leiden. Islamabad Pakistan: Lok Virsa Publication Hous.

Ghasingi, H.F. (2011). Balti Grammar Oor Boolchal. Rawalpini Pakistan: Umar Interprize

Haspelmath, M. and Simd, A. (2010). Understanding Morphology.London: Hodder Education.

Hassan, G.L. (1995). Short Sketch of Balti Grammar. London: Published by Institute of Linguistics University of Berne.

Ismail, M. (2010). Identification of Problematic Sounds for Balti Students. Islamabad Pakistan: Unpublished thesis National University of Modern Languages.

Pandey, A. (2011). Introducing Another Script for Writing Balti Rawalpindi Pakistan: TS Printers Gawalmandi.

Singh, S., and Sarma, V. M. (2011).Verbal Inflection in Hindi. 25th Pacific Asia Conference on Language, Information and Computation, pages 283-292

Yousuf, M.H. (1985). History of Balti language. Skardu, Pakistan: Baltistan Printer Publisher New Bazar Skardu.

Yule, G. (2010).The Study of Language. Fourth Edition. New York: Cambridge University Press. 